RESEARCH REPORT

\title{
Health status of Gypsies and Travellers in England
}

\section{Glenys Parry, Patrice Van Cleemput, Jean Peters, Stephen Walters, Kate Thomas, Cindy Cooper}

J Epidemiol Community Health 2007;61:198-204. doi: 10.1136/jech.2006.045997

\begin{abstract}
Objective: To provide the first valid and reliable estimate of the health status of Gypsies and Travellers in England by using standardised instruments to compare their health with that of a UK resident non-Traveller sample, drawn from different socioeconomic and ethnic groups, matched for age and sex.

Design: Epidemiological survey, by structured interview, of quota sample and concurrent age-sex-matched comparators.

Setting: The homes or alternative community settings of the participants at five study locations in England.

Participants: Gypsies and Travellers of UK or Irish origin $(n=293)$ and an age-sex-matched comparison sample $(n=260)$; non-Gypsies or Travellers from rural communities, deprived inner-city White residents and ethnic minority populations.

Results: Gypsies and Travellers reported poorer health status for the last year, were significantly more likely to have a long-term illness, health problem or disability, which limits daily activities or work, had more problems with mobility, self-care, usual activities, pain or discomfort and anxiety or depression as assessed using the EuroQol-5D health utility measure, and a higher overall prevalence of reported chest pain, respiratory problems, arthritis, miscarriage and premature death of offspring. No inequality was reported in diabetes, stroke and cancer.

Conclusions: Significant health inequalities exist between the Gypsy and Traveller population in England and their non-Gypsy counterparts, even when compared with other socially deprived or excluded groups, and with other ethnic minorities.
\end{abstract}

See end of article for authors' affiliations

Correspondence to:

Professor G Parry, School of

Health and Related

Research, University of

Sheffield, Regent Court 30

Regent Street, Sheffield S1

4DA, UK:

g.d.parry@sheffield.ac.uk

Accepted 15 August 2006
$\mathrm{T}$ here is a lack of reliable research evidence on the health status of adult Gypsies and Travellers in England ${ }^{1-4}$ and no well-designed epidemiological research, most studies being small, localised and descriptive. These studies indicate high infant mortality and perinatal death rates, ${ }^{5}{ }^{6}$ low birth weight, ${ }^{6}$ low immunisation uptake ${ }^{67}$ and high child accident rate. ${ }^{6}$ Practitioner accounts cite health problems that are attributed partly to adverse environmental conditions: accidents, gastroenteritis, upper respiratory infections and otitis media. ${ }^{8-10}$ There is little robust evidence on the comparative health status of adult Gypsies and Travellers, with data only available from Ireland, ${ }^{11}$ our own pilot study in Sheffield ${ }^{12}$ and the confidential enquiry into maternal deaths in the UK. ${ }^{13}$

The 1987 national study of Travellers' health status in Ireland ${ }^{11}$ reported a high death rate for all causes and lower life expectancy for Irish Travellers: women 11.9 years and men 9.9 years lower than the non-Traveller population. Our pilot study of 87 Gypsies and Travellers matched for age and sex with indigenous working class residents in a socially deprived area of Sheffield, ${ }^{12}$ reported statistically and clinically significant differences between Gypsies and Travellers and their nonGypsy comparators in some aspects of health status, and significant associations with smoking and with frequency of travelling. The report of the Confidential Enquiries into Maternal Deaths in the UK, 1997-1999, found that Gypsies and Travellers have "possibly the highest maternal death rate among all ethnic groups". ${ }^{13}$

The people who are referred to as Gypsies and Travellers in this paper comprise English Gypsies, Welsh Gypsies, Scottish Gypsy Travellers and Irish Travellers. Each of these groups has a separate ethnic identity that is particularly evident from their different languages, but they share many aspects of a common cultural identity as traditional Travellers or Romani people. Our study excluded New Age Travellers, who have opted for an alternative lifestyle but are not of the same culture, and European Roma, comparatively recent migrants to Britain.
Estimates of the numbers of Gypsies and Travellers in Britain are imprecise, there are no census data, and other methods (eg, caravan counts) give only approximate numbers. Best estimates suggest that there are around 300000 Gypsies, ${ }^{14}{ }^{15}$ suggesting that this is a significant minority ethnic group. As the dearth of reliable information contributes to their historical neglect in public health policy and planning, this study was designed to provide the first valid and reliable estimate of the comparative health status of Gypsies and Travellers in England.

Previous work guided the choice of comparison group. Our pilot study gave a preliminary indication that Gypsies and Travellers had poorer health than their white settled counterparts living in an inner city and much poorer health than is normative for higher socioeconomic groups. ${ }^{12}$ In this study, we wished to make a more robust and stringent comparison, testing the hypothesis that these health inequalities are greater than one would expect simply on the basis of socioeconomic disadvantage or ethnic minority group membership. In addition to allowing comparison with normative UK health status data, the present study therefore makes concurrent comparisons with groups sharing key characteristics related to possible sources of variance in health. Not all the comparators were poor or from ethnic minorities; we also included a settled rural and semi-rural population of mixed socioeconomic status as a comparison group with non-urban lifestyles. Multivariate and subgroup analysis will be reported in a further paper.

\section{HYPOTHESIS}

The null hypothesis is that the health of Gypsies and Travellers would be similar to that of a sample, matched pairwise for age and sex, drawn from groups in different ways comparable in terms of social disadvantage, ethnic group membership or nonurban lifestyle.

Abbreviations: EQ-5D, EuroQol-5 dimensions; QALYs, quality-adjusted life years 


\section{METHODS}

\section{Sample and sample size}

As no statistics about the size or demographic composition of the Gypsy and Traveller population in England are available, the lack of a sampling frame rules out probabilistic sampling methods. Instead, we quota-sampled across accommodation types, sex, age and ethnic subgroups within the Gypsy and Traveller population, and compared them with a concurrent English-speaking non-Traveller sample, matched for age and sex. To enable planned comparisons and later multivariate analyses, we included other ethnic minorities, White people from socially deprived inner-city populations, and a socioeconomically mixed rural and urban population.

Gypsies and Travellers were sampled from five localities (Sheffield, Leicester, Norfolk, London and Bristol), both sexes, Irish or British, across roadside, official, private and housed accommodation sites. We then attempted to match each Gypsy or Traveller to an English-speaking non-Traveller of the same age and sex. The comparison group comprised: (1) Low socioeconomic status white residents (English or Irish) from a socially deprived urban area; (2) English residents of mixed socioeconomic status from both rural and inner city communities; (3) British Muslim residents of Pakistani origin of mixed socioeconomic status and (4) British Black people of African Caribbean origin of mixed socioeconomic status.

Our study focus was adult English-speaking ethnic groups of Gypsies and Travellers. For this reason, New Age Travellers and Roma refugees from Europe, who are likely to experience different social and cultural influences on health, were excluded. Children aged $<16$ years were also excluded.

Sample size was calculated using the EuroQol-5 dimensions (EQ-5D) health utility measure (described fully in the Measures section) as the primary outcome and data from a pilot study, ${ }^{11}$ which suggested a difference of 0.14 (SD 0.48) in EQ-5D scores between Travellers and a comparison group of poor White inner city dwellers. Assuming similar levels of variability in the main study, to have $90 \%$ power to detect a 0.10 difference in EQ-5D utility scores between Gypsies and Travellers and their age-sex-matched comparison group as significant at the 5\% (two-sided) level would require 250 Gypsies or Travellers' interviews paired with age-sex-matched controls. For secondary analysis of different subgroups, assuming equal numbers per category, 83 Gypsies and Travellers would be required for the study to have an $80 \%$ power to detect a 0.15 difference in EQ-5D scores between the subgroups and their matched controls. On the basis of this power calculation, we planned to interview a minimum of 250 Gypsies and Travellers with quotas (minimum, $\mathrm{n}=83$ ) for each of: men and women; Irish and British; across roadside, official and housed accommodation sites. No quota was set for private sites or for geographical location.

Participants were identified through the knowledge of local health visitors ${ }^{\mathrm{i}}$ or other community services and recruited at their site of residence. Health visitors with specific responsibility for this group were our primary access point because they see all Gypsies and Travellers who arrive in their area to assess health needs. We specifically asked them to approach as wide a group as possible and not to target those with known ill health. Traveller education services and networking within the Gypsies and Travellers' community were secondary sources of access.

iHealth visitors work closely with family doctors (general practitioners) in England. They are community nurses trained in child development and social aspects of health and disease, who are notified of all mothers who have given birth in their area. They typically visit the family at home one month after childbirth to assess their health and social-care needs. They are the only community practitioners who routinely visit homes and focus on ill health prevention for all families.
To take account of Gypsy and Traveller population movement and seasonal variations to responses, each location was visited in each of the four seasons over the fieldwork phase.

Comparison subjects were recruited from the lists of general practices including two inner-city deprived areas with socioeconomically disadvantaged groups identified by postal code. Comparators from ethnic minorities were recruited through participating general practices in those localities with high numbers of the required group. Irrespective of whether the individual had consulted the general practitioners, letters of invitation were sent from the general practice to individuals of the required age and sex, inviting them to participate in the research. This method was supplemented by invitation by health visitors and through researchers attending local community groups. If an individual declined to participate, a second matched control was substituted and so on.

Research governance approval (including multicentre research ethics committee ethical review) was obtained with secondary approval from primary care trusts and local research ethics committees in each location where health visitors worked. Gypsies and Travellers were involved in developing and conducting this study, and in the interpretation of results.

\section{Measures}

The primary measure was the EQ-5D, ${ }^{16}$ a brief, generic health status measure (sometimes described as a health-related quality-of-life measure). It defines health in terms of five dimensions, (mobility, self-care, usual activity, pain or discomfort, anxiety or depression) with each rated at one of three levels, (no problem, some problem, extreme problem). Each possible combination of levels from each dimension yields a total of 243 health states, which are scored on a tariff derived from a general population valuation study. ${ }^{17}$ This scale is standardised from 0 (representing death) to 1 (perfect health), although some states are rated as "worse than death" (ie, less than 0). The EQ-5D also includes a Visual Analogue Scale scored from 0 (worst imaginable health state) and 100 (best imaginable health state). As a descriptive measure of health, the EQ-5D has been used in national health surveys in England, from which age/sex norms have been established for the general population, ${ }^{18}$ and comparative data are also available for different population subgroups. ${ }^{19}$ It is a multi-attribute health utility measure, allowing the calculation of qualityadjusted life years (QALYs) as a standard metric across different groups.

Secondary outcomes included the two census questions on limiting long-term illness and general health, and questions on health symptoms and illnesses. For three of these, standardised measures were used, as follows: respiratory symptoms (Medical Research Council Respiratory Symptom Questionnaire), ${ }^{20} 12$ questions with binary (yes/no) responses, and algorithms for chronic cough, chronic sputum, bronchitis and asthma; chest pain (Rose Angina scale) ${ }^{21}$ defines possible angina according to standard criteria the site of pain or discomfort includes either the sternum (any level) or the left anterior chest and the left arm; it is provoked by either hurrying or walking uphill or walking on the level; making the subject either stop or slacken pace, unless nitrates are taken; disappearing within 10 min from the time the subject stands still; stroke, ${ }^{22}$ a four-item measure with binary (yes/no) responses.

\section{Data analytical methods}

Frequency distributions were obtained for all categorical data, and means and standard deviations or medians and interquartile ranges were calculated for continuous data. Statistical comparisons between groups were conducted using nonparametric tests such as $\chi^{2}$ and Wilcoxon matched pairs or 
McNemar's test for the age-sex-matched data variables. Both unmatched and matched pairs t tests were used as appropriate.

\section{RESULTS}

\section{Recruitment}

In all, 293 Gypsies and Travellers were recruited across the five locations, of which 260 were age and sex matched with a comparator. Quotas were met for ethnic group (English and Irish), sex and accommodation site, with the exception of a shortfall of three housed Travellers. Table 1 shows the numbers of Gypsies and Travellers recruited by sex, ethnicity, accommodation and location, by quota required and by travelling pattern plus numbers of comparators by ethnicity and location.

\section{Demographic profile}

The demographic profile of the 260 age-sex-matched Gypsies and Travellers did not differ significantly from the full sample recruited of 293. Although comparators were recruited to match existing Gypsy or Traveller participants with respect to sex and age (within 3 years) in the final sample, the Gypsies or Travellers were approximately 4 months younger. For both groups, 88 men and 172 women were interviewed. Table 2 presents sociodemographic data for all respondents.

There was a striking educational inequality between the two groups. Fewer Gypsies and Travellers had attended school, either at all, or on a regular basis, or through any form of further education. Only $44 \%$ received regular formal education after primary school, compared with $85 \%$ of comparators. The average age of leaving school was 12.6 years for Gypsies and Travellers and 16.4 years for comparators.

Significantly more Gypsies and Travellers were current smokers than the age-sex-matched counterparts, with the proportion of smokers varying by age.

Significantly more Gypsies and Travellers were the main carer for a dependent relative with a chronic illness or disability, and there was a particularly marked difference in the proportions of Gypsies and Travellers and comparators caring for someone aged between 17 and 64 years (9.6\% vs $2.3 \%$ ).

Table 1 Recruitment by quota variables

\begin{tabular}{lcc}
\hline Gypsies and Travellers & Quota & Total \\
\hline Sex & 83 & 102 \\
$\quad$ Male & 83 & 191 \\
Female & & \\
Ethnicity & 83 & 139 \\
English/Welsh & 83 & 141 \\
Irish & 13 \\
Other & & \\
Site & & 96 \\
Council & 83 & 33 \\
Private & 83 & 84 \\
Unauthorised & 83 & 80 \\
$\quad$ Housed & & 71 \\
Travel (miss=3) & & 75 \\
$\quad$ Travel all year & & 144 \\
Travel in the summer & & 293 \\
Rarely travel now & & \\
Total & & 147 \\
Comparators & 59 \\
$\quad$ White & & 53 \\
Pakistani & \\
Black Caribbean & \\
Other & & \\
Total & & 262 \\
\hline
\end{tabular}

Gypsies and Travellers reported having significantly more children than comparators, irrespective of whether mothers or fathers of the children were interviewed.

\section{General health}

Gypsies and Travellers reported poorer health status over the last year than their age-sex matched-comparators $(z=-4.77$, $\mathrm{p}<0.001$ ) (table 3). Overall, Gypsies and Travellers were significantly more likely to have a long-term illness, health problem or disability, which limits their daily activities or work $\left(\chi^{2}=6.25, p=0.009\right)$, compared with their age-sex matched comparators (table 3 ). The difference in proportions was $11 \%$ (95\% CI 3, 19\%). The Gypsies and Travellers had a slightly higher prevalence of accidents in the previous 6 months (that had caused them to see a doctor or go to hospital), but absolute numbers were small and differences were not significant.

In terms of their health on the day of completion of the questionnaire, Gypsies and Travellers had more problems with mobility, self-care, usual activities, pain or discomfort, and anxiety or depression as assessed using the EQ-5D than their age-sex-matched comparators.

Gypsies and Travellers reported statistically significant worse health status than their age-sex-matched comparators. Mean scores in the overall tariff for the EQ-5D were 0.75 for Gypsies and Travellers (range -0.35 to +1 ) and 0.87 (range -0.09 to +1 ) for the comparators, a mean difference of 0.12 (95\% CI 0.07 to $0.16 ; \mathrm{t}=4.93, \mathrm{p}<0.001)$.

There were also significant differences between Travellers and comparators in the five separate components of the EQ-5D, and the Visual Analogue Scale where the Gypsies and Travellers had significantly lower scores than the control group, a difference of 8.8 (95\% CI 5.1 to 12.5 ).

\section{SPECIFIC ILLNESSES OR PROBLEMS}

Given a list of specific illnesses or problems and a set of validated condition-specific questions, both groups were asked which of these limited their daily activities or work. For most conditions, the prevalence was significantly higher for Gypsies and Travellers compared with their age-sex-matched comparators (table 3). Exceptions were diabetes, stroke and cancer, where rates were low and there were no observed differences.

\section{Maternal health}

All analyses of maternal health examined the rates only in the two groups with children: 150 Gypsies and Travellers and 141 comparators, although in these groups, the Gypsy and Traveller mothers had more pregnancies and deliveries. There was no significant difference between the number of Gypsy and Traveller women, and comparison women reporting a number of problems with pregnancy or childbirth, such as morning sickness, preterm birth, breech presentation or post-natal depression. However, significantly more Gypsies and Travellers experienced one or more miscarriages: 43 (29\%) Gypsy and Traveller women compared with 18 (16\%), of the comparison group with children $\left(\chi^{2}=11.09, \mathrm{p}<0.001\right)$. Conversely, hypertension was less commonly reported by the Gypsy and Traveller women-2 (1\%) compared with 11(8\%) of comparators (Fisher exact $\mathrm{p}=0.007$ ).

\section{Premature death of offspring}

All the women in the two matched samples were asked the question "Are all your children still living?" as a woman without children might have lost a child. Of 172 women in each group, 23 Gypsy and Traveller women (6.2\%) answered in the negative (excluding miscarriages) compared with none of the comparators $\left(\chi^{2}=16.9, p<0.001\right)$. Details on the cause of death were missing for seven women, but nine Gypsies and Travellers 
Table 2 Sociodemographic information on Gypsies and Travellers and comparators

\begin{tabular}{|c|c|c|c|c|}
\hline Variable & & $\begin{array}{l}\text { Gypsies and } \\
\text { Travellers, n=260 }\end{array}$ & $\begin{array}{l}\text { Comparators, } \\
n=260\end{array}$ & $\begin{array}{l}\text { Age-sex-matched } \\
\text { p value }\end{array}$ \\
\hline Age (years) & Mean (SD) (range) & $38.1(15.4)(16-87)$ & $38.4(15.2)(16-82)$ & 0.017 \\
\hline \multirow[t]{3}{*}{ School education } & n (\%) Attended school at all & $171(65.8)$ & $228(87.7)$ & $<0.001$ \\
\hline & $\mathrm{n}(\%)$ Attended regularly after primary school & $115(44.2)$ & $221(85)$ & $<0.001$ \\
\hline & Age (years) stopped attending school, mean (SD) & $12.6(2.7)$ & $16.4(1.5)$ & $<0.001$ \\
\hline \multirow[t]{2}{*}{ Further education } & $\mathrm{n}(\%)$ with any post- 16 education & $11(4.2)$ & $164(63)$ & $<0.001$ \\
\hline & $\mathrm{n}(\%)$ graduates or near equivalent & $0(0)$ & $74(28.5)$ & \\
\hline \multirow[t]{4}{*}{ Smoking status } & n Current:ex:never & $147: 46: 60$ miss 7 & $56: 59: 138$ & $<0.001$ \\
\hline & $\%$ Current, age $16-35$ years & 64 & 26 & \\
\hline & $\%$ Current, age $36-55$ years & 54 & 20 & \\
\hline & $\%$ Current, age $56-75$ years & 38 & 9 & \\
\hline Main carer for ill or disabled relative & $\begin{array}{l}\mathrm{n}(\%) \text { (broken down by age of dependent } \\
\text { relative: }<16: 17-64: \geqslant 65 \text { years) }\end{array}$ & $41(15.8)(9: 25: 6)$ & $21(8.1)(5: 6: 10)$ & 0.013 \\
\hline Women: number of children & Mean number of children (SD) (range) & $4.3(3.6)(0-20)$ & $1.8(1.4)(0-7)$ & $<0.001$ \\
\hline Men:number of children & Mean number of children (SD) (range) & $5.2(3.7)(1-18)$ & $2.6(2)(1-13)$ & $<0.001$ \\
\hline
\end{tabular}

reported one or more stillbirths or deaths of a neonatal infant, with one woman experiencing multiple stillbirths.

\section{Health differences between the ethnic subgroups of Gypsies and Travellers}

There were no statistically significant differences in health between the ethnic subgroups of Gypsies and Travellers (Irish Travellers compared with English, Scottish or Welsh Gypsies), over a range of symptoms (depression, angina, chronic cough, chronic sputum, bronchitis and asthma), health status in the last year or long-term illness. There were no differences between the Irish Travellers and the Gypsies for four of the five components of the EQ-5D with the exception of the item on anxiety/depression, where $25 \%$ and $18 \%$ of Irish and the others, respectively, were moderately anxious/depressed, and $12 \%$ and $5 \%$ were extremely anxious/depressed $\left(\chi^{2}=7.27, \mathrm{df}=2\right.$, $\mathrm{p}=0.026)$.

\section{Health differences between Gypsies and Travellers in different accommodation types}

Gypsies and Travellers with long-term illness ( $n=101 / 242$; $42 \%)$ are more likely to be living in a trailer on a council site $(54 \%)$ or in a house $(45 \%)$ than on a private site $(39 \%)$ or on empty land $\left(30 \% ; \chi^{2}=9.14, p=0.03\right)$. The same pattern is found for the EQ-5D tariff scores, with those on private sites or empty land reporting better health status $(\mathrm{F}=4.33, \mathrm{p}=0.005)$. Other physical health problems did not differ significantly by accommodation.

Travelling patterns showed an even stronger relationship with health, with those who rarely travelled $(n=125 / 256 ; 49 \%)$ having the worst health status, in terms of health in past year $\left(\chi^{2}=34.57, \mathrm{p}<0.001\right)$, long term illness $\left(\chi^{2}=15.04, \mathrm{p}=0.001\right)$, chronic cough $\left(\chi^{2}=8.34, \mathrm{p}=0.02\right)$, EQ-5D tariff $(\mathrm{F}=13.09$, $\mathrm{p}<0.001)$ and Visual Analogue Scale scores $(\mathrm{F}=6.76$, $\mathrm{p}<0.001)$.

\section{DISCUSSION}

Results indicate that this sample of Gypsies and Travellers had significantly poorer health status and more self-reported symptoms of ill health than other UK-resident, English speaking ethnic minorities and economically disadvantaged white UK residents. On the standardised measure EQ-5D, the health status of these Gypsies and Travellers is worse than that of their age-sex matched comparators. Self-reported chest pain, respiratory problems and arthritis were also more prevalent in the Traveller group.

In the Gypsy Traveller group, we found a relationship between health, accommodation type and travelling pattern.
However, it is not possible from these data to determine whether accommodation and travelling patterns have an effect on health or vice versa. Those with poorer health status may choose or be constrained to live in a house or travel rarely. On the other hand, living in a house or on a council site, and travelling rarely, may have a negative effect on health. With the exception of the question on depression and anxiety in EQ-5D, we found no difference in the health of Gypsies compared with Irish Travellers. It is beyond the scope of this paper to consider health status variance in the Gypsies and Travellers' group further, and we have not reported subgroup analyses or used multivariate analytical methods to explore sources of variance across the total sample. These results will be reported in a further paper.

The scale of health inequality between the study population and the UK general population is even larger. In the 2001 census, the proportion of the population overall (all ages) reporting limiting long-term illness is $18.2 \%$ compared with $41.9 \%$ in the Gypsies and Travellers' group in our survey. Compared with other local and national data, bronchitis, asthma and angina were much more prevalent. For example, nearly five times as many Gypsies and Travellers reported symptoms of chronic bronchitis than a general population in Sheffield, ${ }^{22}$ and over twice as many reported asthma-like symptoms or symptoms of angina. The aspects of health that show the most marked inequality are self-reported anxiety, respiratory problems including asthma and bronchitis, and chest pain.

The scale of the difference of 0.12 in average index values on the EQ-5D may be more tangible when translated into differences in QALYs between the two groups by multiplying their life expectancy by the index value. Assuming that people in each group experienced the average index value of their group and that, on average, people lived up to 75 years, the comparison group would enjoy 62.25 QALYs in their lifetime, compared with 56.25 QALYs in the Gypsies and Travellers' group. This difference of nine QALYs is substantial, comparable with the difference between the highest and lowest social classes in the UK. (The quality-adjusted life expectancy at birth of someone in social classes 1 and 2 is nearly 66 QALYs, but for someone in social classes 4 and 5, it is only about 57 QALYs. $)^{23}$ Furthermore, the magnitude of the difference would be even larger if account is taken of the lower life expectancy of Gypsies and Travellers. ${ }^{11}$

The finding of a large health inequality in Gypsies and Travellers leaves open the question of whether these differences are attributable to the observed sociodemographical differences between the Gypsies and Travellers and the comparison sample, 
Table 3 Comparisons between Gypsies and Travellers and age-sex-matched comparators on standardised general health status measures and numbers reporting specific illnesses and problems

\begin{tabular}{|c|c|c|c|c|}
\hline Health variable & $\begin{array}{l}\text { Gypsies and Travellers, } \\
\mathrm{n}=\mathbf{2 6 0}\end{array}$ & $\begin{array}{l}\text { Comparators, } \\
n=260\end{array}$ & $\begin{array}{l}\text { Age-sex matched } \\
\text { p Value }\end{array}$ & \\
\hline \multicolumn{5}{|l|}{ Health status over past year } \\
\hline & $\begin{array}{l}103(40 \%) \\
80\end{array}$ & $\begin{array}{l}147(57 \%) \\
76\end{array}$ & & \\
\hline Not good & 77 & 37 & $<0.001 \dagger$ & \\
\hline \multicolumn{5}{|l|}{ Long-term illness } \\
\hline Yes & $101 / 242(42 \%)$ & $75 / 242(31 \%)$ & 0.009 & \\
\hline $\begin{array}{l}\text { Accidents in the past } 6 \text { months "which caused } \\
\text { you to see a doctor or go to hospital?" }\end{array}$ & $34 / 260$ (13\%) & $22 / 260(8 \%)$ & 0.112 & \\
\hline \multicolumn{5}{|l|}{$\begin{array}{l}\text { Health on day of interview } \\
\text { Mobility }\end{array}$} \\
\hline $\begin{array}{l}\text { No problems } \\
\text { Some problems } \\
\text { Confined to bed }\end{array}$ & $\begin{array}{l}196(75 \%) \\
64(25 \%) \\
0(0 \%)\end{array}$ & $\begin{array}{l}222(85 \%) \\
38(15 \%) \\
0(0 \%)\end{array}$ & $002 \dagger$ & \\
\hline $\begin{array}{l}\text { Self-care } \\
\text { No problems } \\
\text { Some problems } \\
\text { Unable to perform }\end{array}$ & $\begin{array}{l}232(89 \%) \\
17(7 \%) \\
11(4 \%)\end{array}$ & $\begin{array}{l}250(96 \%) \\
7(3 \%) \\
3(1 \%)\end{array}$ & $0.002 \dagger$ & \\
\hline $\begin{array}{l}\text { Usual activities } \\
\text { No problems } \\
\text { Some problems } \\
\text { Unable to perform }\end{array}$ & $\begin{array}{l}203(78 \%) \\
46(18 \%) \\
11(4 \%)\end{array}$ & $\begin{array}{l}227(87 \%) \\
28(11 \%) \\
5(2 \%))\end{array}$ & $002 \uparrow$ & \\
\hline $\begin{array}{l}\text { Pain/discomfort } \\
\text { No pain } \\
\text { Moderate pain } \\
\text { Extreme pain }\end{array}$ & $\begin{array}{l}173(67 \%) \\
50(19 \%) \\
37(14 \%)\end{array}$ & $\begin{array}{l}188(72 \%) \\
60(23 \%) \\
12(5 \%)\end{array}$ & $0.004 \dagger$ & \\
\hline $\begin{array}{l}\text { Anxiety/depression } \\
\text { Not anxious } \\
\text { Moderately anxious } \\
\text { Extremely anxious }\end{array}$ & $\begin{array}{l}186(72 \%) \\
52(20 \%) \\
22(8 \%)\end{array}$ & $\begin{array}{l}218(84 \%) \\
36(14 \%) \\
6(2 \%)\end{array}$ & $0.001 \dagger$ & \\
\hline Mean EQ-5D tariff score (SD) & $0.75(0.36)$ & $0.87(0.23)$ & $<0.001^{*}$ & \\
\hline $\begin{array}{l}\text { Illness/problems identified from specific question } \\
\text { Chest pain/discomfort } \\
\text { Possible angina } \\
\text { Chronic cough } \\
\text { Chronic sputum } \\
\text { Bronchitis } \\
\text { Asthma } \\
\text { Anxiety }\end{array}$ & $\begin{array}{l}88 / 260(34 \%) \\
78 / 260(30 \%) \\
127 / 260(49 \%) \\
119 / 260(46 \%) \\
107 / 260(41 \%) \\
168 / 260(65 \%) \\
100 / 255(39 \%)\end{array}$ & $\begin{array}{l}57 / 260(22 \%) \\
51 / 260(20 \%) \\
43 / 260(17 \%) \\
38 / 260(15 \%) \\
26 / 260(10 \%) \\
105 / 260(40 \%) \\
33 / 255(13 \%)\end{array}$ & $\begin{array}{r}0.004 \\
0.008 \\
<0.001 \\
<0.001 \\
<0.001 \\
<0.001 \\
<0.001\end{array}$ & \\
\hline & Difference $(95 \% \mathrm{Cl})$ \\
\hline $\begin{array}{l}\text { Illnesses/problems reported after prompting } \\
\text { Nerves } \\
\text { Arthritis } \\
\text { Asthma } \\
\text { Eye/vision problems }\end{array}$ & $\begin{array}{l}73 / 260(28 \%) \\
57 / 260(22 \%) \\
56 / 260(22 \%) \\
28 / 260(11 \%)\end{array}$ & $\begin{array}{l}10 / 260(4 \%) \\
25 / 260(10 \%) \\
14 / 260(5 \%) \\
9 / 260(4 \%)\end{array}$ & $\begin{array}{r}<0.001 \\
<0.001 \\
<0.001 \\
0.003\end{array}$ & $\begin{array}{l}24 \%(18-30 \%) \\
12 \%(7-18 \%) \\
17 \%(11-22 \%) \\
7 \%(3-12 \%)\end{array}$ \\
\hline $\begin{array}{l}\text { Bronchitis/emphysema } \\
\text { Heart disease including angina } \\
\text { Hearing problems } \\
\text { Rheumatism } \\
\text { Diabetes } \\
\text { Stroke } \\
\text { Cancer }\end{array}$ & $\begin{array}{l}27 / 260(10 \%) \\
20 / 260(8 \%) \\
16 / 260(6 \%) \\
15 / 260(6 \%) \\
11 / 260(4 \%) \\
3 / 260(1 \%) \\
2 / 260(1 \%)\end{array}$ & $\begin{array}{l}5 / 260(2 \%) \\
9 / 260(4 \%) \\
8 / 260(3 \%) \\
3 / 260(1 \%) \\
9 / 260(4 \%) \\
2 / 260(1 \%) \\
6 / 260(2 \%)\end{array}$ & $\begin{array}{r}<0.001 \\
0.035 \\
0.152 \\
0.008 \\
0.824 \\
1.000 \\
0.289\end{array}$ & $\begin{array}{l}8 \%(4-13 \%) \\
4 \%(1-8 \%) \\
3 \%(-1 \% \text { to } 7 \%) \\
5 \%(1-8 \%) \\
0 \%(-3 \% \text { to } 4 \%) \\
0 \%(-3 \% \text { to } 2 \%) \\
-1 \%(-4 \% \text { to } 1 \%)\end{array}$ \\
\hline
\end{tabular}

which was better educated, less likely to smoke, had fewer children and were less likely to be caring for a dependent relative. Multivariate analysis will explore this issue in a further paper.

Reported rates for major diseases of stroke, cancer and diabetes were found to be equally low in both groups. Although it is harder to detect low prevalence conditions with this sample size and premature death amongst Gypsies and Travellers could contribute to this finding, it is possible that there is a genuine lack of health inequality in these illnesses. Alternatively, as cancer and type II diabetes tend to be "silent" diseases until their later stages, they may have been under-reported in the Gypsies and Travellers' group through ignorance of the diagnosis. ${ }^{24}$ Similarly, although Gypsy and Traveller women had experienced more miscarriages and stillbirths, there was no excess of other reported complications of pregnancy and childbirth. The retrospective reporting of these complications may have influenced this.

These results must be interpreted in the light of the methodological limitations of this study. The first concerns the representativeness of the sample. In the absence of any data on the sociodemography of the total population and given the 


\section{What is already known?}

- Descriptive studies and practitioner accounts suggest excess health problems in Gypsy and Traveller communities, with an emphasis on child health, high infant mortality and maternal death rates, low birth weight, low immunisation uptake and high child-accident rates.

- Although poorer health has been linked to socioeconomic disadvantage and ethnic minority group status, there is a lack of research evidence on the health status of adult Gypsies and Travellers in England. practical difficulties of access, it was not possible to obtain a probability sample. Instead, we recruited a quota sample, primarily through health visitors, potentially introducing bias. People in transit and staying for short periods in roadside encampments were harder to contact, and these were found to have better health than those who were housed or living in a trailer on a council site. However, even those who travelled quite often and were interviewed on the roadside had poorer health than the comparator group. Although we asked health visitors not to pre-select on the basis of health problems, and repeated checks were made that they had tried not to do so, there may have been some unconscious bias, plus structural reasons why people available and willing to be interviewed could have poorer health, with the exception of those acutely ill. On the other hand, compared with those who live in or spend time in areas not served by specialist healthcare professionals, our sample probably had better access to healthcare provision and hence potentially better treatment. This suggests the opposite bias, although the nomadic nature of our sample means that many would have lived in areas that are less well-served. In any case, alternative procedures for gaining access to the study population would, in our judgement, have created even more problems with representativeness.

Another limitation is that it was not feasible to assess accurately the socioeconomic status of the population. This was both a practical and a conceptual difficulty. Asking these sensitive and culturally inappropriate questions would have significantly reduced cooperation with the health interview. In addition, this community has its own economic subsystem to some extent, which makes such assessment conceptually questionable. We do not make the assumption that Gypsies and Travellers (or the other ethnic minorities) were economically impoverished, although we included comparators from economically disadvantaged areas to make planned comparisons between subgroups (not reported in this paper). Although we cannot therefore estimate how socioeconomically comparable the groups were, the inclusion of an economically disadvantaged subgroup provides the most rigorous test of the null hypothesis.

Because we used self-report measures, there is a risk that the findings of excess prevalence of health problems in the Gypsies and Travellers was influenced by differential over-reporting in that group compared with the comparison group. The qualitative study conducted and reported in parallel with this survey, ${ }^{24}$ throws light on this. Here, widespread cultural attitudes of stoicism and minimisation of health problems, while not quantitatively assessed, do imply that over-reporting is not the most likely explanation. For example, in some conditions, cultural attitudes are likely to lead to late diagnosis and avoidance of any knowledge of the diagnosis, favouring underreporting. On balance, for policy purposes, we believe that the results do not overestimate health difficulties for the population as a whole.
What this study adds?

- Gypsies and Travellers report poorer health on standardised measures than comparable groups of residents from socially deprived inner city areas, other ethnic minorities and rural residents.

- Poorer health status was reported in relation to long-term illness, health problems that limit daily activities or work, health-related quality of life, chest pain, respiratory problems, arthritis, miscarriage and premature death of offspring.

With the exception of some conditions such as stroke, where the baseline frequency was low in both populations, health inequalities were reported for a wide range of mental and physical heath problems. The findings confirm the impression from practice-based evidence on poorer health in Gypsies and Travellers' populations, as summarised by Doyal et al. ${ }^{1}$ Our findings indicate marked health inequalities on standardised measures between the Gypsy and Traveller population in England and their non-Gypsy counterparts, even when compared with other socially deprived or excluded groups and with other ethnic minorities.

\section{ACKNOWLEDGEMENTS}

We should thank the following people: Gypsy and Traveller participants and all those Gypsies and Travellers attending the feedback forums who freely gave their time and support to this study; Ann Bagehot, Secretary of The Gypsy Council, and Gypsy Travellers Richard O'Neill, Mally Dow, Mary Lee and Len Smith, advisory group members; Tommy Doherty and Josie Lee, two Travellers who made significant contributions to this work, but who sadly died before the study was completed; the late Charles Smith, Chair of The Gypsy Council; Health Visitors Lynne Hartwell, Sarah Rhodes, Jackie Mosley, Teresa Murray, Rachael Wilson and Val Dumbleton, advisory group members and those who arranged access to Gypsy Travellers; Patricia Anderson, Jackie Gleeson, Becky Taylor, Rosemary Hasler who conducted the health status interviews; Professor Paul Dolan for specialist advice on the EQ-5D and Dr Nick Payne for specialist advice when planning the quantitative study.

\section{Policy Implications}

- We expect improvements in the policy response to the needs of this neglected minority in the light of these findings. Those responsible for public health policy and planning cannot assume that the health needs of Gypsies and Travellers are met by existing policy in relation to other ethnic minorities and socially disadvantaged groups.

- Strong ethnic identity, and coherent cultural beliefs and attitudes, underpin health-related behaviour in this group, and health experiences need to be understood in this context, alongside the specific effect of the social and economic hardship, and social exclusion.

- Health data are important in monitoring health and evaluating the effects of health interventions, and Gypsies and Travellers should be included in routine ethnic monitoring.

- The provision of effective healthcare and improvement of poor health in Gypsies and Travellers requires multiagency awareness and joint working to discuss the negative effects both of adverse social experiences and attitudinal barriers to health. 


\section{Authors' affiliations}

Glenys Parry, Patrice Van Cleemput, Jean Peters, Stephen Walters, Cindy

Cooper, School of Health and Related Research, University of Sheffield, Sheffield, UK

Kate Thomas, School of Healthcare, Baines Wing, University of Leeds, Leeds, UK

Funding: Funding was received from the Department of Health. The views expressed in this publication are those of the authors and not necessarily those of the Department of Health.

Competing interests: None.

\section{REFERENCES}

1 Doyal L, Cameron A, Cemlyn S, et al. The health of Travellers in the South West region. South West Public Health Observatory 2002.

2 Hajioff S, McKee M. The health of the Roma people: a review of the published literature. J Epidemiol Community Health 2000;54:864-9.

3 Feder GS. Traveller Gypsies and primary care. J R Coll of Gen Pract 1989;39:425-9.

4 Zeman CL, Depken DE, Senchina DS. Roma health issues: a review of the literature and discussion. Ethn Health 2003:8:223-249.

5 Linthwaite P. The health of Traveller mothers and children in East Anglia. London: Save the Children, 1983.

6 Pahl J. Vaile M. Health and health care among Travellers. J Soc Policy 1986; 17:195-213.

7 Feder GS, Vaclavik T, Streetly A. Traveller Gypsies and childhood immunization: a study in east London. Br J Gen Pract 1993;43:281-4.
8 Taylor J. Travellers. Health behaviour and beliefs. Health Visit 1991:64:223-4.

9 Lawrie B. Travelling families in east London-adapting health visiting methods to a minority group. Health Visit 1983;56:26-28.

10 Batstone J. Meeting the health needs of Gypsies. Nurs Stand 1993:7:30-2.

11 Barry J, Herity B, Solan J. The Travellers' health status study, vital statistics of travelling people, 1987. Dublin: Health Research Board, 1987.

12 Van Cleemput P, Parry G. Health status of Gypsy Travellers. J Public Health Med $2001 ; 23: 129-34$

13 Lewis G, Drife J. Why mothers die 1997-1999: the confidential enquiries into maternal deaths in the United Kingdom 41. London: RCOG Press, 2001.

14 Liegeois JP. Gypsies \& Travellers. Strasbourg: The Council of Europe, 1987.

15 Crawley H. Moving forward: the provision of accommodation for Travellers and Gypsies. London: Institute for Public Policy Research, 2004:6.

16 Kind P, Dolan P, Williams A. Euroqol EQ-5D user guide. Version A (6/96). York: Centre for Health Economics, University of York, 1996.

17 Dolan P. Modelling valuations for Euroqol health states. Med Care 1997:35:351-63.

18 Kind P, Dolan P, Gudex C, et al. Variations in population health status: results from a United Kingdom national questionnaire survey. BMJ 1998;316:736-41.

19 Kind P, Hardman G, Macran S. UK population norms for EQ-5D discussion paper 172. York: Centre for health economics, University of York, 1998.

20 Medical Research Council. MRC Committee on Environmental and Occupational Health: questionnaire on respiratory symptoms. London: MRC, 1986.

21 Rose G, McCartney P, Reid DD. Self-administration of a questionnaire on chest pain and intermittent claucidation. Br J Prev Soc Med 1977;31:42-8.

22 Sheffield Primary Care Trusts Informatics Service. Sheffield health \& illness survey 2. Sheffield: Sheffield Health Authority, 2000.

23 Williams A. Intergenerational equity: an exploration of the 'fair innings' argument. Health Econ 1997;6:117-32.

24 Van Cleemput P, Parry G, Thomas K, et al. Health-related beliefs and experience of Gypsies and Travellers: a qualitative study. J Epidemiol Community Health 2007;61:205-10.

\section{bmjupdates+}

bmjupdates+ is a unique and free alerting service, designed to keep you up to date with the medical literature that is truly important to your practice.

bmjupdates+ will alert you to important new research and will provide you with the best new evidence concerning important advances in health care, tailored to your medical interests and time demands.

Where does the information come from?

bmjupdates+ applies an expert critical appraisal filter to over 100 top medical journals A panel of over 2000 physicians find the few 'must read' studies for each area of clinical interest

Sign up to receive your tailored email alerts, searching access and more...

www.bmjupdates.com 
PostScript

\section{BOOK REVIEWS}

\section{Hair in toxicology: an important bio- monitor}

Edited by Desmond John Tobin. Published by The Royal Society of Chemistry, Cambridge, 2005, \$199, pp 355. ISBN 0-85404-587-2

Hair in Toxicology: an important bio-monitor is a scientific and practical book. Hair testing began slowly about 28 years ago, initiated perhaps by Baumgartner's pioneering article. Sachs suggested an erratic growth thereafter, with a "gold rush" period between 1986 and 1992, typified by relatively uncritical use of hair testing, followed by a "hang over" period between 1992 and 1996 characterised by more critical reflection. It seems that a renewed "gold rush" - at least of published papers if not of conclusive results-began thereafter. Hair allegedly offers one crucial potential advantage when compared with-for example, blood or urine as a medium for divination-the long time window. Whereas blood and urine can only indicate use for a few days, hair offers the possibility of retrospective use examination for at least several months. A number of other advantages of using hair are sometimes cited (difficult to falsify, easy to store, lengthy shelf life, low body invasion, etc.). Hair analysis is used as a tool in the detection of xenobiotics (drug of abuse, pharmaceuticals, environmental contaminants, etc), forensic science, traffic occupational medicine and clinical toxicology. The subject of analytical testing in hair has always had an element of controversy due to perceived problems of environmental exposure, among other areas of concern, and Hair in Toxicology: an important bio-monitor takes on these issues in a direct manner.

The book begins with a brief but nice preface by Dr Desmond John Tobin and contains four parts. It starts out by telling us about the biology of hair (the biogenesis and growth of human hair; the anatomy, biosynthesis, physical properties, pigmentation and abnormalities of the hair shaft). Many figures enhance the information given by the text. The second part of the book is an excellent review regarding the application of hair biology in environmental assessments. The application of hair biology in forensic toxicology and human identification is discussed. The authors present several forensic cases where hair analysis has indicated drug-facilitated crimes. Then, the book briefly summarises the toxicology and kinetics of metals in relation to hair, presents the relative advantages and disadvantages of hair compared with other biomarkers of exposure to metals and considers situations where hair analysis may be indicated to monitor or document human exposure to metals. It also discusses the misuses of "commercial" hair tests for panels of metals and minerals whose results are promoted as indicators of health, nutritional status and metal toxicity. Tables help to summarise complex concepts wherever necessary. An appropriately broad range of metal toxicity is covered, from the viewpoints of both symptoms and signs. The last two chapters of part two provide information about the advantages and limitations of hair fibre analysis as a biomarker of human exposure to environmental pollutants and trace elements; advantages and problems associated with the use of hair as a study tissue; and diseases associated with changes in hair composition. These chapters provide a step-bystep discussion of the above information by reviewing different human studies as well as by providing easy-to-understand figures and tables.

Hair in toxicology: an important bio-monitor tells us not only about how hair can serve as a biomarker for toxicity and exposure but also about how the different hair care products can affect the body. In the third part of the book the chemistry of hair care products and their potential toxicological issues are discussed. Finally, in part four, an interesting chapter on the value of hair in bio-archaeology - for example, hair as an indicator of past diet and population movement or as an indicator of exposure to pollutants, and as a record of drug or micronutrient use. A practical aspect of this book is that testing procedures and the interpretation and clinical use of hair analysis are described for the related subjects in several chapters.

Overall, the general appearance of the book is satisfactory. The clarity of the figures is appropriate. The index is thorough, and I found it relatively easy to use. The accuracy and coverage of the references, by all of the authors, are good. Copious references are included with each chapter. Abbreviations are explained as they appear in the text. Numbering the tables and figures according to the chapter gives a better correlation This book, with adequate references, gives sufficient information to meet the needs of advanced undergraduates and graduate students. This is also suitable for biologists, toxicologists, pharmacologists, nutritionists and a variety of students who wish to obtain additional knowledge of hair analysis. Many of the authors of this book are wel known in the fields of environmental health sciences, toxicology, biomedical sciences, analytical chemistry, occupational health medicine, industrial medicine and archaeological research and represent an almost even split between European and American contributors. It is my opinion that this book complements the previous text, regarding hair analysis, nicely.

With all my experience in this branch of medicine I highly recommend this text to al toxicologists. Sections in this text should also be reviewed by doctors who see patients with chronic toxicity. People who have had chronic exposure to toxic substances may also find chapters in this book helpful.

N Eizadi Mood

\section{Handbook for good clinical research practice (GCP): guidance for implementation}

Published by the World Health Organization Geneva, 2005, pp 125 (softcover) + CD. ISBN 92-4-159392

Ever thought good clinical practice (GCP) dull? Ever felt abbreviated out? Well, I'd like to report that the WHO's Handbook for good clinical practice (GCP): guidelines for implementation is an antidote to the mind-boggling stream of acronyms bandied about in research and development departments throughout the world, and that it provides an interesting and amusing narrative on the current minefield that constitutes Research Governance..

Well, as the title might suggest, it was a bit of a long shot.

Research and development managers, finance departments, data protection officers and ethics committees now form a formidable team apparently dedicated to snuffing out the life of a research idea at conception. They have had to become familiar with the requirements of GCP, mandatory in this country since March 2004. The research community is slowly catching up. Transforming research from its cottage industry status, where anyone can have a go, has been a traumatic experience for many researchers. It remains so in some cases, and "own account" studies on investigational medicinal product are becoming a rarity. GCP, of course, applies to any study involving human subjects, not just to drug or device trials. The business of research governance is now bedded down in many trusts, especially the larger ones, and is operating reasonably smoothly. It is easy to forget, however, especially when attempting to get an investigational medicinal product study off the ground, that GCP regulations are actually intended to improve the quality of research and the safety of patients. In most cases, this is exactly what they have achieved. The handbook acts as a useful reminder of the essential philosophy underpinning the bureaucracy.

It provides a concise and clear description of the 14 principles underlying GCP as well as guidance on their implementation in practice. The roles and responsibilities of the various stakeholders in the research process are also described. There are many sources used, the eight most important of which are on an accompanying $\mathrm{CD}$. It follows the research process through the development of the proto$\mathrm{col}$ and standard operating procedures, support systems and trial-related documentation, selection of trial sites, ethics approval, through to data management and reporting. Each step in the process has relevant GCP principles, which need to be borne in mind.

Naturally, the handbook is written for an international audience and will only ever act as useful background to your local GCP training. Nevertheless, it is background that I'd recommend to serious triallists and health services researchers.

Andy Barton

\section{CORRECTIONS}

doi: 10.1136/jech.2006.045997corr l

G Parry, P Van Cleemput, J Peters, et al. The health status of Gypsies and Travellers in England ( $J$ Epidemiol Community Health 2007;61:198-204). The unlocked logo and text stating that this paper is freely available online under the BMJ Journals unlocked scheme was erroneously omitted from this paper. We apologise for this error.

Mutaner C, Chung HJ. Psychosocial epidemiology, social structure, and ideology (J Epidemiol Community Health 2005:59:540-1). The surname of the first author of this paper was spelt incorrectly and should be Muntaner. We apologise for this error. 